\title{
MEASURING SUPERSTITIOUS BELIEF: WHY LUCKY CHARMS MATTER
}

\author{
Richard Wiseman ${ }^{1}, \&$ Caroline Watt ${ }^{2}$ \\ ${ }^{1}$ University of Hertfordshire \\ ${ }^{2}$ University of Edinburgh
}

\begin{abstract}
A large body of research has attempted to develop theories about the function and origin of superstitious beliefs on the basis of the psychological correlates of such beliefs. Most of this work has measured superstitious belief using the Paranormal Belief Scale (PBS), and has tended to find that superstitious belief is associated with poor psychological adjustment such as low self-efficacy and high trait anxiety. However, the PBS refers solely to negative superstitions (e.g., breaking a mirror will cause bad luck) and omits items referring to positive superstitions (e.g., carrying a lucky charm will bring good luck). Positive superstitions may serve different psychological functions to negative superstitions. Indeed, as with other forms of "positive illusions", beliefs in positive superstitions may be psychologically adaptive. This paper reports two studies investigating this neglected aspect of the psychological correlates of superstitious belief. If positive and negative superstitious beliefs serve different psychological functions, then we might expect, using Analysis of Variance, to find interactions between superstition type, and various relevant individual difference measures. Study 1 was a large-scale Internet-based study which investigated the relationship between endorsement of superstition type, gender, and a single-item measure of neuroticism. Participants were asked to indicate the degree to which they endorsed three negative and three positive superstitious beliefs using five response options (anchored with Definitely Yes and Definitely No). The three negative items were: "Have you avoided walking under a ladder because it is associated with bad luck?"; "Would you be anxious about breaking a mirror because it is thought to cause bad luck?"; and, "Are you superstitious about the number 13?". The three positive items were: "Do you say 'fingers crossed' or actually cross your fingers?"; "Do you say 'touch wood' or actually touch or knock on wood"; and, "Do you sometimes carry a lucky charm or object?". 4,339 individuals took part in study 1 . The highly statistically significant results found interactions between gender and endorsement of superstition type, and between neuroticism and superstition type. Study 2 was conducted by mail, and sought to replicate and extend the findings obtained in Study 1 by administering validated questionnaire measures of neuroticism and life satisfaction alongside positive and negative superstition items. 116 individuals took part. As with study 1, there was a significant interaction between gender and superstition type, but no interaction was found for neuroticism. A significant interaction was found between superstition type and life satisfaction. Overall, these findings indicate that the psychological correlates of superstitious belief vary depending on whether the belief is in positive or negative superstitions. These findings have important implications for theory development, demonstrate that the PBS is an incomplete measure of superstitious belief, and highlight the need for future measures to include items referring to positive superstitions.
\end{abstract}

\section{INTRODUCTION}

Paranormal, superstitious and magical beliefs have been found in a diverse range of cultures for thousands of years (Jahoda, 1969), and polls show that these beliefs continue to thrive in modern times (Newport \& Strausberg, 2001). Researchers have long speculated about the origins and functions of such beliefs (see, e.g., Frazer, 1922; Jahoda, 1969; Malinowski, 1948; Vyse, 1997). Over the last two decades, almost all of this work has involved attempting to identify reliable psychological, and behavioural, correlates of such beliefs (Irwin, in press). This line of enquiry was stimulated by the publication of the Paranormal Belief Scale (PBS) in the mid-1980s (Tobacyk \& Milford, 1983; Tobacyk, 1988). The PBS was the first measure of paranormal belief to be psychometrically evaluated and, although there has been some recent debate over its factorial structure (e.g., Lawrence, 1995; Tobacyk \& Thomas, 1997) and internal validity 
(Lange, Irwin, \& Houran, 2000), it continues to be the most widely-used measure of paranormal belief (Goulding \& Parker, 2001).

A significant amount of this research has centered around just one of the seven PBS sub-scales, namely, belief in superstition. A large body of work has demonstrated that, almost without exception, the psychological correlates of this sub-scale reflect relatively poor psychological adjustment, including low selfefficacy (Tobacyk \& Shrader, 1991); high trait anxiety (Wolfradt, 1997); irrational beliefs (Roig et al., 1998); an external locus of control (Dag, 1999; Tobacyk, Nagot \& Miller, 1988); magical ideation (Thalbourne, Dunbar, \& Delin, 1995; Tobacyk \& Wilkinson, 1990); psychopathology (Dag, 1999); field dependence and suggestibility (Hergovich, 2003); and dissociative experiences (Wolfradt, 1997). Gender differences have also emerged, with women tending to show higher levels of superstitious beliefs than men (e.g., Dag, 1999; Vyse, 1997; Wolfradt, 1997).

These findings have been used by some researchers as a basis for various theoretical models attempting to explain the prevalence of superstitious thinking, with almost all of this work exploring the role played by such thinking in the initiation and maintenance of maladaptive beliefs and behaviour (e.g., Alcock, 1981; Dag, 1999; Vyse, 1997). For instance, many authors have suggested that paranormal and superstitious beliefs may develop in anxious individuals with a strong need for control, in an attempt to overcome perceived uncertainty in their surroundings (Irwin, 2000; Jahoda, 1969; Malinowski, 1948), or as a coping mechanism following traumatic childhood experiences (French \& Kerman, 1996; Irwin, 1992; Lawrence et al., 1995; Ross \& Joshi, 1992). This model is supported by recent theoretical developments within cognitive and emotion research, suggesting that anxiety plays a central role in negative emotions (Brown, Chorpita, \& Barlow, 1998), and that childhood experiences of diminished control may lead to the development of anxiety (Chorpita \& Barlow, 1998).

The superstition sub-scale of the PBS contains three items: 'Black cats can bring bad luck'; 'If you break a mirror, you will have bad luck'; and, 'The number "13" is unlucky'. All of these items refer to beliefs that can be classified as "negative" superstitions - that is, they all reflect the notion that certain behaviours (e.g., breaking a mirror) or omens (e.g., seeing a black cat) are magically associated with unlucky and potentially harmful consequences. Given that this is the case, it is perhaps not surprising that, as noted above, scores on this sub-scale correlate with a range of measures reflecting poor psychological adjustment. However, not all superstitious beliefs fall into this category. Some, such as carrying a charm to bring good luck, touching wood, and crossing fingers, reflect a desire to bring about beneficial consequences by actively courting good luck or at least avoiding bad luck. Such "positive" superstitions may serve different psychological functions to negative superstitions. Indeed, as is the case with other forms of so-called 'positive illusions' (Taylor, 1989), beliefs in these types of superstitions may actually be psychologically adaptive rather than maladaptive. Unfortunately, almost all previous work into the correlates of superstitious belief has used the PBS, and is thus based on an instrument only measuring negative superstitions. As such, this research, and the theoretical work driven by the results of this work, may have failed to explore a vitally important aspect of superstitious thinking. Although a few authors have remarked upon the potential theoretical and practical importance of positive superstitious beliefs (Irwin, in press; Tills, cited in Haining, 1990; Vyse, 1997), we are not aware of any research that has investigated this question empirically. The present paper addresses this issue. Participants were asked to complete several individual difference measures and then indicate the degree to which they endorsed negative and positive superstitions. It was hypothesised that Analysis of Variance (ANOVA) would reveal interactions between superstition type and individual difference measures.

The present paper reports on two studies. Study 1 was a large-scale internet-based study which investigated the relationship between endorsement of superstition type, gender, and a single-item measure of neuroticism. Study 2 sought to replicate and extend the findings obtained in Study 1 by administering validated questionnaire measures of both neuroticism and life satisfaction. 


\section{STUDY 1 METHOD}

In March 2003, the first author initiated a two-month-long, Internet-based study into superstitious beliefs, as part of an on-going research program into the psychology of luck. The study was promoted through British National Science Week, by articles in broadsheet newspapers which invited members of the public to visit a website and complete a questionnaire. The present analyses examined the resulting database to discover whether the main measures of individual differences used during the study interacted with participants' belief in negative and positive superstitions.

\section{Questionnaire}

Participants were first asked to indicate basic demographic information about themselves, including their age (Categories: Under 20; 21-30; 31-40; 41-50; Over 50) and gender. They were then asked to indicate their agreement with a single-item measure of self-perceived neuroticism ("I tend to worry about life") via five response options anchored with Strongly Agree (scoring 5) and Strongly Disagree (scoring 1). Finally, participants were asked to indicate the degree to which they endorsed three negative and three positive superstitious beliefs using five response options (anchored with Definitely Yes and Definitely No). The three negative items concerned walking under a ladder ('Have you avoided walking under a ladder because it is associated with bad luck?), breaking a mirror ('Would you be anxious about breaking a mirror because it is thought to cause bad luck?') and the number 13 ('Are you superstitious about the number 13?'). The three positive items concerned crossing fingers ('Do you say "fingers crossed" or actually cross your fingers?'), touching wood ('Do you say "touch wood" or actually touch or knock on wood?') and carrying a lucky charm ('Do you sometimes carry a lucky charm or object?').

\section{STUDY 1 RESULTS}

Participants. 4,339 participants took part in the study, 1951 males and 2388 females. There were 450 individuals in the 'under 20 years' age group, 965 in the '21-30' category, 995 in the ' $31-40$ 'category, 902 in the ' $41-50$ ' category, and 1027 in the 'over 50 years' category.

Scoring. Responses to each of the superstition items were transformed into a 5-point scale (ranging from 5 - Definitely Yes, to 1 - Definitely No). The scores relating to the three positive items were summed to provide a measure of the degree to which participants endorsed these superstitions. Likewise, scores relating to the three negative items were summed to provide the same measure for these superstitions. For all participants, the mean neuroticism score was $2.7(\mathrm{SD}=1.2)$. To obtain the clearest possible picture of individual differences for the measure of self-perceived neuroticism, only those who responded at the extreme ends of the scale (i.e., responding 'Strongly Agree' or 'Strongly Disagree') were included in the analyses. There were 536 participants in the 'high' self-perceived neuroticism group, and 309 in the 'low' group (see table 1 for further details).

\begin{tabular}{lccc}
\hline & $\mathrm{N}$ & $\begin{array}{c}\text { Positive } \\
\text { Superstition }\end{array}$ & $\begin{array}{c}\text { Negative } \\
\text { Superstition }\end{array}$ \\
\hline Gender & & & \\
$\quad$ Male & 1951 & $8.0(3.4)$ & $6.4(3.6)$ \\
$\quad$ Female & 2388 & $10.1(3.0)$ & $8.0(3.9)$ \\
Self-perceived neuroticism & & & \\
$\quad$ High neuroticism & 536 & $10.0(3.5)$ & $8.7(4.1)$ \\
$\quad$ Low neuroticism & 309 & $7.6(3.4)$ & $5.2(3.1)$ \\
\hline
\end{tabular}

Table 1: Study 1 descriptive statistics: Number $(\mathrm{N})$ of participants, and mean positive and negative superstition scores (Standard Deviation in parentheses), for each individual difference measure. 
Sampling method. The methodological issues surrounding Internet-mediated research (IMR) have been the topic of recent debate within psychology. Some researchers have questioned whether internet-accessed samples are representative of more general populations (see, e.g., Schmidt, 1997), whilst others have argued that IMR usually results in samples that are as representative as those associated with more traditional research paradigms (see, e.g., Hewson, 2003). To help address this issue, the authors examined whether the patterns of belief in negative superstitions within the present data-set matched those reported in previous research. As reported above, past work with the PBS has indicated that women are more superstitious than men, and that people who are anxious are more superstitious than those who are not. The present data-set found the same significant patterns: women exhibited significantly higher belief in negative superstitions than men $(F[1,4337]=191.31, p<.0001$, eta $=.21)$; and, the Spearman Rank correlation coefficient between self-perceived neuroticism and belief in negative superstitions for all participants was both positive and significant $(\mathrm{N}=4339$, Rho [corrected for ties] $=.27, p[2$ tailed] $<.0001)$. These patterns provide strong evidence that the data-set obtained in this study was not dissimilar to the data-sets used in this type of research in the past.

Gender. A 2x2 ANOVA (superstition type $\mathrm{x}$ gender) revealed a highly significant main effect of gender: women tended to endorse both types of superstition to a greater extent than men $(F[1,4337]=379.5$, $p<$ .0001 , eta $=.28)$. Overall, positive superstitions were endorsed more than negative superstitions, $(F[1,4337]$ $=1259.69, p<.0001$, eta $=.47)$. There was also a highly significant interaction, whereby the difference between the genders narrowed for negative superstitions $(F[1,4337]=20.40, p<.0001$, eta $=.07)$.

Self-perceived neuroticism. A $2 \times 2$ ANOVA (superstition type $\mathrm{x}$ self-perceived neuroticism) revealed a highly significant main effect of neuroticism: high neurotics endorsed both types of superstition more strongly than low neurotics $(F[1,843]=163.7, p<.0001$, eta $=.40)$. There was also a highly significant interaction $(F[1,843]=19.42, p<.0001$, eta $=.15)$, such that the difference between the groups narrowed for the positive superstitions ${ }^{1}$.

\section{STUDY 1 DISCUSSION}

Study 1 was a large-scale internet study which investigated whether the psychological correlates of endorsing positive versus negative superstitions might differ. Using analysis of variance, the study examined interactions between belief in positive and negative superstitions, and two measures of individual differences (gender and self-perceived neuroticism). Interactions were found for these individual difference measures, indicating that it is indeed theoretically important for questionnaire measures of superstitious belief to include and differentiate between negative and positive superstitions.

One limitation of study 1 is its use of a single-item indicator of self-perceived neuroticism, which may only have face validity. It was therefore decided to conduct a second study, using a well-established questionnaire measure of neuroticism. Study 1 also was limited in that it took only neuroticism as a measure of psychological adjustment. As noted in the introduction, superstitious belief has traditionally been linked to a wide variety of indicators of poor psychological adjustment. However, in line with the recent surge of popularity in 'positive psychology', we thought it interesting to examine the potential relationship between superstition type and a validated measure of life satisfaction.

\footnotetext{
${ }^{1}$ It could be argued that people might say "touch wood" or "fingers crossed" through habit and not because they are superstitious. To investigate this issue, we carried out two post-hoc ANOVAs comparing the question relating to lucky charms with the three combined negative superstition items. The results continued to show significant interaction effects for both individual difference measures (Gender $F[1,4337]=89.98, p<.0001$, et $a=.14$; Self-perceived neuroticism $F[1,843]=106.41, p<.0001$, eta $=.33$ ) strongly suggesting that the original results from the combined measure of positive superstition were not solely due to the "touch wood" and "fingers crossed" items.
} 


\section{STUDY 2 METHOD}

Study 2 examined whether the degree to which people endorse different types of superstition (negative versus positive) may vary according to three individual difference measures: gender, neuroticism, and life satisfaction. A volunteer panel built up by the first author through his research into luck, was contacted by email and invited to participate in a postal questionnaire study about superstition and luck. Questionnaires were sent out, and completed questionnaires were returned in postage-paid envelopes.

\section{Questionnaires}

The questionnaire pack consisted of three questionnaires. Questionnaire One was the 48-item Revised Eysenck Personality Questionnaire short scale (EPQ-R) (Eysenck \& Eysenck, 1991), a well-established measure which includes 12 items designed to indicate Neuroticism, based on Yes/No answers to short statements. High scores indicate high neuroticism. This questionnaire also asked participants' age and gender. Questionnaire Two was the 5-item satisfaction with life scale (Diener et al., 1985), in which participants respond to each statement on a 7-point scale (response options anchored with strongly disagree and strongly agree). High scores indicate high satisfaction with life. Questionnaire Three was the same superstition questionnaire as was used in study 1 (see above for details of content and scoring).

\section{STUDY 2 RESULTS}

Participants. 153 questionnaire packs were sent out, and completed questionnaires were returned by 116 participants, giving a $76 \%$ response rate. There were 28 male respondents, 77 females, mean age 42 years, $\mathrm{SD}=10.12$, range $25-66$ years. 11 respondents did not give their gender, and are therefore not included in the gender analyses below. Overall mean neuroticism score was $5.7(\mathrm{SD}=3.8)$ and overall mean life satisfaction score was $21.8(\mathrm{SD}=8.5)$.

Analysis. For the purpose of analysis of variance, participants were split into "high" or "low" neuroticism groups, and "high" or "low" life satisfaction groups, according to a median split for each variable. There were 61 participants in the high neuroticism group (mean $=8.8, \mathrm{SD}=2.1$ ), 55 in the low neuroticism group $($ mean $=2.2, \mathrm{SD}=1.8), 66$ in the high life satisfaction group (mean $=28.1, \mathrm{SD}=3.6$ ), and 50 in the low life satisfaction group (mean $=13.4, \mathrm{SD}=5.2$ ). Mixed ANOVAs were conducted between the two measures of superstitious belief (positive versus negative) and the measures of gender, neuroticism, and life satisfaction (see table 2 for descriptive statistics).

\begin{tabular}{lccc}
\hline & $\mathrm{N}$ & $\begin{array}{c}\text { Positive } \\
\text { Superstition }\end{array}$ & $\begin{array}{c}\text { Negative } \\
\text { Superstition }\end{array}$ \\
\hline Gender & & & \\
$\quad$ Male & 28 & $7.9(3.9)$ & $7.0(3.4)$ \\
$\quad$ Female & 77 & $9.6(3.6)$ & $7.1(3.6)$ \\
Neuroticism & & & \\
$\quad$ High neuroticism & 61 & $10.3(3.4)$ & $8.4(3.6)$ \\
$\quad$ Low neuroticism & 55 & $8.0(3.8)$ & $5.8(3.0)$ \\
Life satisfaction & & & \\
$\quad$ High satisfaction & 66 & $9.2(3.8)$ & $6.6(3.5)$ \\
$\quad$ Low satisfaction & 50 & $9.3(3.7)$ & $8.0(3.6)$ \\
\hline
\end{tabular}

Table 2: Study 2 descriptive statistics: Number (N) of participants, and mean positive and negative superstition scores (Standard Deviation in parentheses), for each individual difference measure. 
Gender. A 2x2 ANOVA (superstition type $\mathrm{x}$ gender) revealed that, as with study 1, women tended to endorse superstitious beliefs more highly than men (see table 2 for details). However, the trend did not reach significance in study 2 , perhaps due to relatively low statistical power $(F[1,103]=1.43, p=.23$, et $a=$ .12). Also, as before, positive superstitions received higher levels of endorsement than negative superstitions $(F[1,103]=21.07, p<.0001$, eta $=.41)$. Study 2 replicated the finding of study 1 of an interaction between superstition type and gender: the difference between men and women in endorsement of positive superstitions narrowed dramatically for negative superstitions $(F[1,103]=4.83, p=.03$, et $a=.21)$.

Neuroticism. A $2 \times 2$ ANOVA (superstition type $\times$ neuroticism) found a significant main effect for neuroticism $(F[1,114]=18.86, p<.0001$, eta $=.38)$. This replicated the finding in study 1 that high neurotics tend to endorse both types of superstitious beliefs more highly than low neurotics. However, unlike study 1 , study 2 found no interaction between superstition type and neuroticism $(F[1,114]=.31, p=$ .58 , eta $=.05)^{2}$. The overall correlation between neuroticism and belief in negative superstitions in the present data-set again supported the findings from previous research $(N=116$, Rho [corrected for ties] $=.39$, $p[2$ tailed $]<.0001)$. The Spearman Rank correlation coefficient between the $\mathrm{N}$ and $\mathrm{L}$ scales on the EPQ- $\mathrm{R}$ was non-significant, suggesting that the results were not unduly influenced by dissimulation $(N=116$, Rho [corrected for ties] $=-.08, p[2$ tailed $]=.38$ ).

Life satisfaction. A $2 \times 2$ ANOVA (superstition type $\mathrm{x}$ life satisfaction) found a tendency for individuals low in life satisfaction to endorse superstitions more highly, however the trend was not significant $(F[1,114]$ $=1.55, p=.22$, eta $=.12$ ). A significant interaction was found, whereby the difference between the life satisfaction groups dramatically reduced for positive superstitions $(F[1,114]=4.30, p=.04$, eta $=.19)$.

\section{GENERAL CONCLUSIONS}

The vast majority of research examining the psychological correlates of superstitious belief has used the superstition sub-scale of the PBS. This sub-scale contains three items, all of which refer to negative superstitions. We present two studies examining potential difference in patterns of belief for positive and negative superstitions. Significant interactions were found, for four out of five analyses, with effect sizes ranging from .07 to .21 . These findings raise questions about the validity of previous research and have theoretical and methodological implications for future research.

On a theoretical level, these results have important implications for those wishing to understand why people hold superstitious beliefs. As noted towards the start of this paper, almost all of the theoretical work in this area has viewed superstitious thinking within the context of the initiation and maintenance of maladaptive beliefs and behaviour. The significant interactions found in the present studies underline the importance of expanding this theoretical understanding to take account of both positive and negative superstitions. The required expansion maybe relatively small and easily incorporated into traditional models associating superstitious belief with psychological maladjustment. This would be the case if, for example, future research revealed that the mechanisms underlying belief in positive superstitions are conceptually similar to those that drive belief in negative superstitions. Alternatively, belief in positive superstitions could have their basis in quite different mechanisms, such as the promotion of self-efficacy and optimism, and thus may only be fully explained via theoretical approaches that are substantially different to existing models.

\footnotetext{
${ }^{2}$ Median split was chosen for this analysis in study 2 in order to maximise statistical power. To enable further comparison with study 1 , which used extreme scorers on the neuroticism measure, a post hoc analysis was conducted for study 2 taking approximately the top and bottom $25 \%$ of neuroticism scorers. There were 32 in the "low" neuroticism group (mean $\mathrm{N}=0.9, \mathrm{SD}=0.8$ ) and 35 in the "high" neuroticism group (mean $\mathrm{N}=10.4, \mathrm{SD}=1.2$ ). Analysis of Variance showed no significant interaction between neuroticism and superstition type $(F[1,65]=.06, p=.80$, et $a=.03)$. Therefore this post hoc analysis also did not replicate the interaction found in study 1.
} 
On a methodological level, these findings strongly suggest that it is important that any valid measure of superstitious belief includes reference to both positive and negative superstitions. The frequently-used PBS superstition sub-scale fails to do this, and thus there is a pressing need for the patterns found in previous studies using the scale to be interpreted as correlates of belief in negative superstitions, rather than superstition per se.

Future research should aim to develop a broader measure of belief that encompasses much wider, and much more diverse, forms of superstitions. There is clearly a need for a more fine-grained understanding of the psychological functions of different superstition types, beginning with the fundamental positive versus negative distinction that we have highlighted in this paper.

\section{ACKNOWLEDGEMENTS}

The authors are grateful to Professor Ian Deary, Professor Harvey Irwin, and Professor Robert Morris, for their helpful comments on an earlier draft of this manuscript. This research was supported by the PerrottWarrick Fund and the Koestler Parapsychology Unit.

\section{REFERENCES}

Alcock, J. E. (1981). Parapsychology: Science or Magic? A Psychological Perspective. Elmsford, NY: Pergamon Press.

Brown, T. A., Chorpita, B. F., \& Barlow, D. H. (1998). Structural relationships among dimensions of the DSM-IV anxiety and mood disorders and dimensions of negative affect, positive affect, and autonomic arousal. Journal of Abnormal Psychology, 107, 179-192.

Chorpita, B. F., \& Barlow, D. H. (1998) The development of anxiety: The role of control in the early environment. Psychological Bulletin, 124, 3-21.

Dag, I. (1999). The relationships among paranormal beliefs, locus of control and psychopathology in a Turkish college sample. Personality and Individual Differences, 26, 723-737.

Diener, E., Emmons, R.A., Larson, R.J., \& Griffin, S. (1985). The satisfaction with life scale. Journal of Personality Assessment, 49, 71-75.

Eysenck, H. J., \& Eysenck, S. B. G. (1991). Manual of the Eysenck Personality Scales (EPS Adult). London: Hodder \& Stoughton.

Frazer, J. G. (1922). The Golden Bough. London: Macmillan.

French, C. C., \& Kerman, M. K. (1996). Childhood trauma, fantasy proneness and belief in the paranormal. Paper presented at the Annual Conference of the British Psychological Society, London.

Goulding, A., \& Parker, A. (2001). Finding psi in the paranormal: Psychometric measures used in research in paranormal beliefs/experiences and in research on psi-ability. European Journal of Parapsychology, 16, 73-101.

Hergovich, A. (2003). Field dependence, suggestibility and belief in paranormal phenomena. Personality and Individual Differences, 34, 195-209.

Hewson, C. (2003). Conducting research on the Internet. The Psychologist, 16, 290-293.

Irwin, H. J. (1992). Origins and functions of paranormal belief: The role of childhood trauma and interpersonal control. Journal of the American Society for Psychical Research, 86, 199-208.

Irwin, H. J. (2000). Belief in the paranormal and a sense of control over life. European Journal of Parapsychology, 15, 6878.

Irwin, H. J. (in press). The Psychology of Paranormal Belief. Parapsychological Monographs No. 20. New York: Parapsychology Foundation.

Jahoda, G. (1969). The Psychology of Superstition. Harmondsworth, England: Penguin. 
Lange, R., Irwin, H. J., \& Houran, J. (2000). Top-down purification of Tobacyk's revised Paranormal Belief Scale. Personality and Individual Differences, 29, 131-156.

Lawrence, T. R. (1995). How many factors of paranormal belief are there? A critique of the Paranormal Belief Scale. Journal of Parapsychology, 59, 3-25.

Lawrence, T., Edwards, C., Barraclough, N., Church, S., and Hetherington, F. (1995). Modelling childhood causes of paranormal beliefs and experiences: Childhood trauma and childhood fantasy. Personality and Individual Differences, 19, 209-215.

Malinowski, B. (1948). Magic, Science and Religion. Garden City, NY: Doubleday.

Newport, F., \& Strausberg, M. (2001). Americans' belief in psychic and paranormal phenomena is up over last decade. Princeton: Gallup News Service.

Roig, M., Bridges, K. R., Renner, C. H., \& Jackson, C. R. (1998). Belief in the paranormal and its association with irrational thinking controlled for context effects. Personality and Individual Differences, 24, 229-236.

Ross, C. A., \& Joshi, S. (1992). Paranormal experiences in the general population. Journal of Nervous and Mental Disease, $180,357-361$.

Schmidt, W. C. (1997). World Wide Web survey research: Benefits, potential problems and solutions. Behaviour Research Methods, Instruments and Computers, 29, 270-273.

Taylor, S. E. (1989). Positive Illusions: Creative Self-Deception and the Healthy Mind. New York: Basic Books.

Thalbourne, M. A., Dunbar, K. A., \& Delin, P. S. (1995). An investigation into correlates of belief in the paranormal. Journal of the American Society for Psychical Resarch, 89, 215-231.

Tills, H., cited in Haining, P. (1990). Superstitions. London: Treasure Press.

Tobacyk, J. (1988). A Revised Paranormal Belief Scale. Unpublished manuscript. Louisiana Tech University, Rushton, LA.

Tobacyk, J., \& Milford, G. (1983). Belief in paranormal phenomena: Assessment instrument development and implications for personality functioning. Journal of Personality and Social Psychology, 44, 1029-1037.

Tobacyk, J., Nagot, E., \& Miller, M. (1988). Paranormal beliefs and locus of control: A multidimensional examination. Journal of Personality Assessment, 52, 241-246.

Tobacyk, J., \& Shrader, D. (1991). Superstition and self-efficacy. Psychological Reports, 68, 1387-1388.

Tobacyk, J., \& Thomas, A. (1997). How the big orthogonal seven is really the oblique seven. Journal of Parapsychology, $61,337-342$.

Tobacyk, J., \& Wilkinson, L. V. (1990). Magical thinking and paranormal beliefs. Journal of Social Behavior and Personality, 5, 255-264.

Vyse, S. A. (1997). Believing in Magic: The Psychology of Superstition. New York: Oxford University Press.

Wolfradt, U. (1997). Dissociative experiences, trait anxiety and paranormal beliefs. Personality and Individual Differences, $23,15-19$.

Address for correspondence: Caroline Watt,

University of Edinburgh, Koestler Parapsychology Unit, 7, George Square, Edinburgh EH8 9JZ, UK.

E-mail: caroline.watt@ed.ac.uk 